\title{
ALGUNOS APUNTES SOBRE KANT Y LA LIBERTAD POLÍTICA
}

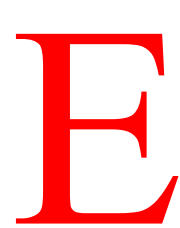

s sobradamente conocido que la obra moral y, jurídico-política de Emmanuel Kant es uno de los lugares a los que, con mayor asiduidad, se ha recurrido desde las discusiones, tanto de índole filosófico-analítica como de carácter directamente político-sustantivo, sobre «los conceptos de libertad».

Que tal cosa ocurra en el ámbito de la cuestión usualmente designada como «el problema metafísico de la libertad de la voluntad»«(del que el mismo autor de la Crítica de la razón pura nos enseñó que su consideración adecuada sólo puede proceder de la ética) no tiene nada de extraño dada la importancia incomparable de la aportación kantiana a aquélla. Pero lo que en éstas páginas me va a ocupar es ese otro terreno, jurídico y político, de la discusión sobre el concepto de libertad en la acción social o -de nuevo en términos del propio Kant- «en el ejercicio externo del arbitrio». Y, en referencia a éste último, no me parece desatinada la opinión de que el recurso a la obra kantiana tiene menos que ver con la magnitud o interés intrínseco de su aportación precisa que con los propios intereses retóricos y polémicos de los teóricos y los militantes de «la libertad positiva y la libertad negativa».

Es, en buena medida, Isaiah Berlin quien, en sus breves pero influyentísimos ensayos sobre la materia, puede muy bien ejemplificar tal tipo de tratamiento. Tras formular, en los sugerentes términos que hoy nos son ya familiares, la diferenciación entre las nociones «negativa» $\mathrm{y}$ «positiva» de libertad, y sostener que una y otra no constituyen «dos interpretaciones distintas de un único concepto, sino dos actitudes profundamente divergentes e irreconciliables ante los fines de la vida», Berlin procede a adscribir al filósofo de Könisberg a las filas (tan nutridas y variopintas como para disfrutar en ellas de la compañía de Spinoza, Locke, Montesquieu, Burke, Rousseau, y «de muchos estudiosos antes que ellos y jacobinos y 
comunistas después que ellos») de aquéllos para quienes el concepto de libertad se refiere centralmente a la determinación del individuo por la propia razón. Pues si bien es verdad que -en «uno de sus tratados políticos»- Kant «estuvo cerca de la afirmación del ideal de libertad negativa», sus convicciones definitivas parecen haber sido las de que, por el contrato originario, «el hombre abandona su libertad salvaje para encontrarla de nuevo íntegra en un estado de dependencia legal» ${ }^{1}$; lo que significa para Berlin (cuyo tenor expositivo manipula los textos kantianos) «que sólo ésta [la dependencia legal] es la verdadera libertad». De este modo, «la libertad, lejos de ser incompatible con la autoridad, deviene virtualmente idéntica a ella» ${ }^{2}$.

La contrapartida a la posición interpretativa de Berlin -pero en el marco del mismo tipo de tratamiento de la cuestión- puede encontrarse en las tesis del no menos venerable filósofo y no menos insigne liberal, Norberto Bobbio. El profesor turinés -que comparte, sin embargo, con Berlin la preferencia por la versión «negativa» o liberal del concepto de libertad y la convicción en la dualidad de concepciones rivales que ésta y la formulación «positiva» del mismo constituyen- ${ }^{3}$ sostiene que las definiciones «rousseaunianas» de la libertad como autonomía colectiva, que Kant presenta -explícita y «desafortunadamente»en sus obras jurídicas y políticas, no bastan para adscribir a este autor tal posición. Por el contrario, la libertad que verdaderamente se «invoca» en su obra, que ésta «convierte en fin de la vida política», y «en la que se inspira su concepción del derecho, del Estado y de la historia, no es la democrática sino la liberal», es decir, la libertad en el sentido negativo o «libertad sin coerción» ${ }^{4}$.

No creo que ninguna de las dos interpretaciones sean suficientemente satisfactorias (aunque, en mi opinión, lo es en bastante mayor medida la de Bobbio) para dar cuenta de las reflexiones sobre la

${ }^{1}$ Véase Kant, Die Metaphysik der Sitten, (primera parte, Rechtslehre) Ak. VI, págs. 315-316; 1989, pág. 146.

${ }^{2}$ Isaiah Berlin, 1969, págs. 166, 153 nota y 148. Versión castellana (1988), págs. 237, 224 nota y 219. El «tratado político» no identificado por Berlin es el breve escrito kantiano Idea de una historia universal en sentido cosmopolita. Vid. Ak. VIII, pág. 22: 1981, págs. 48-49. Berlin se refiere asimismo y con mayor detenimiento al concepto kantiano de «libertad de la voluntad».

${ }^{3}$ En palabras del mismo Bobbio, su trabajo sobre la posición kantiana «tiene también como objetivo confirmar, a través del análisis de un texto célebre, la existencia de las dos nociones fundamentales de libertad, y de mostrar la necesidad de mantener la distinción entre ellas, pues de la preponderancia de una u otra depende la asignación posible de un autor a una corriente de pensamiento político o a otra». 1961 pág. 118.

${ }^{4}$ Bobbio, ibid., págs. 108, 109 y 117. Versión castellana de 1985, págs. 201 y 210. 
libertad jurídica y política contenidas en los escritos kantianos. Sin pretender que en ellos se constituya una construcción teórica detenida, o una aportación original -y recuerdo que sigo refiriéndome específicamente a la teoría de la libertad en el ámbito del derecho y la política-, pienso que sí contiene posiciones más complejas e interesantes de lo que las dualidades rígidas, del tipo de las mencionadas, permiten.

La libertad de la voluntad individual como autonomía, o «en su concepto positivo» según el cual aquélla se determina a la acción convirtiendo en máxima de ésta la ley moral que ella misma establece en tanto racional -y por la que «la razón pura se hace práctica por sí misma»-, queda radicalmente fuera del ámbito de la legislación jurídica, y así de la acción del Estado, ya que no sólo excede de las posibilidades de una y otro, sino que es por su mismo significado contradictoria con la motivación para la acción que caracteriza al derecho (que no puede, por tanto, producir moralidad de las acciones). Esta conocida y celebrada tesis, central a toda la filosofía práctica de Kant, que establece en la autonomía moral del arbitrio el límite negativo del derecho, debe ser de nuevo traída a colación como punto de partida de cualquier aproximación al tema, frente a los que aún tratan de adscribir a este autor la pretensión de un Estado ético que realiza la libertad como autonomía del individuo racional.

Las elaboraciones que presiden el sistema de la Rechtslehre y de toda la Metafísica de las Costumbres - «en tanto que estas leyes morales se refieren a acciones meramente externas y a su conformidad con la ley (Gesetzmäsigkeit) se denominan jurídicas»: «la libertad a que se refieren las leyes jurídicas sólo puede ser la libertad en el ejercicio externo del arbitrio»; el concepto del Derecho «tiene por objeto la relación externa y práctica de una persona con otra y en tanto que sus acciones pueden tener influjo entre sí, bien mediata, bien inmediatamente»- conducen al bien conocido concepto de Derecho como conjunto de condiciones de la conciliación de arbitrios y al Principio universal del mismo, según el cual «una acción es conforme a Derecho cuando según ella o según su máxima, la libertad del arbitrio de cada uno puede conciliarse con la libertad de todos, según una ley general ${ }^{5} \gg$. La libertad objeto de la regulación jurídica, la que el derecho protege o garantiza, y que, en esa medida, se convierte en fundamento de legitimidad del derecho mismo (la coacción jurídica concebida como «obstáculo a un uso de la libertad que es él mismo un obstáculo a la libertad según leyes universales»), es decir, aquélla que por el contrato originario deja de ser «libertad salvaje y sin ley» para convertirse en libertad legítima o conforme a

${ }^{5} A k$. VI, págs. 214 y 230: 1978, págs. 42, 43 y 79-81. 
derecho, es la libertad entendida al modo liberal, de la esfera de acción no interferida por otros, o, en términos del propio Kant, «independencia del arbitrio compulsivo de otra persona $»^{6}$.

Hasta aquí tienen razón Bobbio y los innumerables intérpretes que se inclinan por la misma conclusión. No comparto, sin embargo, la opinión del autor italiano de que sea necesario descartar, como confusiones de Kant respecto de sus propios presupuestos, aquellos momentos de su obra en que Kant vincula directamente la libertad con la legitimidad -en términos de contrato o consentimiento racional- de las leyes que la regulan. El caso paradigmático al respecto es el de la formulación, en La paz perpetua, del «principio de la libertad de los miembros de una sociedad» como primer principio de la constitución republicana»:

«La libertad jurídica -externa, por tanto- no puede definirse, como es costumbre, diciendo que es «la facultad de hacer lo que se quiera, con tal de no perjudicar a nadie». En efecto, ¿qué es la facultad? Es la posibilidad de una acción que no perjudique a nadie. Por tanto, vendría a ser la definición de la libertad la siguiente: «Libertad es la posibilidad de las acciones que no perjudican a nadie». No se perjudica a nadie -hágase lo que se quiera- cuando a nadie se perjudica. Todo esto, como se ve, es mera tautología y juego de palabras. Hay que definir mi libertad exterior (jurídica) como la facultad de no obedecer a las leyes exteriores sino en tanto en cuanto he podido darles mi consentimiento» ${ }^{7}$.

En esos enunciados, para algunos tan desconcertantes o injustificados, se parte de la constatación de que la «libertad legal» o «libertad en el estado jurídico» es, no libertad de otra índole o de distinta «naturaleza» (como algunas lecturas apresuradas de la presentación de la idea de contrato en la Rechtslehre han querido ver), sino libertad bajo leyes del derecho estatal, esto es, libertad necesariamente delimitada o regulada, para su coexistencia con la de otros, por leyes coactivas (tal y como queda claro en la gran mayoría de los enunciados kantianos de la libertad «negativa» que ya conocemos). Y, dado este sometimiento de la libertad a leyes en el estado jurídico, Kant

${ }^{6}$ Carta a Heinrich Jung-Stilling, $A k$. XXIII, pág. 495. En este sentido, y entre otros muchos comentaristas, véase Felipe González Vicén, 1984, págs. 48 y 49, o Norberto Bobbio, 1962, págs. 112-114, 1985, págs. 205-206.

${ }^{7}$ Ak. VIII, pág. 350, nota, traducción castellana, 1979, pág. 102 nota. En la Doctrina del derecho se enuncia como «atributo jurídico» de los ciudadanos del Estado «la libertad legal de no obedecer a ninguna otra ley que a aquélla a la que ha dado su consentimiento». Ak. VI, pág. 314, 1989, pág. 143. 
manifiesta -con cierta imprecisión y ambigüedad semántica pero, que yo vea, sin contradecirse teórica o valorativamente- que esas leyes deben ser solamente aquéllas a las que hemos podido consentir, y que sólo en esa medida se puede decir que los individuos sean libres en el estado jurídico.

$\mathrm{Y}$ debe necesariamente advertirse, frente a lo que algunos críticos como Berlin han dado a entender, que, en los dos lugares controvertidos (en que la libertad política se enuncia en sentido «positivo»). Kant no escribe que la libertad consista en la obediencia a tales leyes universales, esto es, que seamos libres «al obedecer»o en tanto nos sometemos a éstas, sino que somos libres -en relación con la ley- si sólo vemos limitada nuestra libertad, el ejercicio externo del libre arbitrio, por la ley a la que hemos podido prestar consentimiento: aquélla es «la facultad de no obedecer a las leyes exteriores, sitio en tanto en cuanto he podido darles mi consentimiento» o «la libertad legal de no obedecer a ninguna otra ley más que a aquéllas a que hayan dado su sufragio». A esta misma condición, debo recordar, se traduce, en mi opinión, la cláusula de la «ley universal»-o, «según leyes universales»- de tantos enunciados kantianos (y de las mismas formulaciones «negativas» de la libertad consideradas canónicas en su obra).

Ahora bien, si Kant no ofrece en esos lugares una concepción de la libertad política distinta y contrapuesta a la que contiene el núcleo de su doctrina del derecho, ¿qué decir entonces de la aparente crítica frontal a la noción «negativa» de la libertad de la misma nota de La paz perpetua, según la cual «la libertad jurídica -externa, por tanto- no puede definirse, como es costumbre, diciendo que es «la facultad de hacer todo lo que se quiera, con tal de no perjudicar a nadie»? La respuesta a esta pregunta puede resumirse diciendo que Kant no se opone en esas líneas al concepto o «definición» negativa de la libertad, o a su valor, sino que critica como inadecuada o insuficiente una determinada propuesta normativa de la libertad legítima, o del criterio de delimitación de la libertad en un sistema jurídico. Veamos su argumento:

«En efecto ¿qué es la facultad? Es la posibilidad de una acción que no perjudique a nadie. Por tanto, vendría a ser la definición de la libertad la siguiente: «Libertad es la posibilidad de las acciones que no perjudican a nadie». No se perjudica a nadie -hágase lo que se quiera- cuando a nadie se perjudica. Todo esto, como se ve, es mera tautología y juego de palabras».

Parece, pues, verosímil afirmar que Kant no se ocupa en este punto del concepto de la libertad de las acciones en general, sino de 
la libertad jurídica o conforme a derecho (rechtliche), o de la libertad establecida como facultad (Befugnis), es decir, autorizada o ya establecida según ciertos límites por el Derecho. Y lo que aduce es que el ámbito de extensión de esa facultad -de la libertad legítima en el estado jurídico, según la idea de justicia- no puede establecerse en términos de «lo que no perjudique a otro», porque el concepto aquí referido por Kant es el de Unrecht (o laedo), es decir, el de injusticia, violación de un derecho, o trato a otra persona incorrecto o indebido (Unrecht, Wrong), en términos de un criterio normativo-moral o de justicia (de lo permisible en la interacción mutua).

Formulado en esos términos, el argumento kantiano recobra su significado y su plausibilidad crítica; pues es cierto que el enunciado según el cual la libertad legítima (la que debe ser consagrada por el derecho como facultad jurídica), es «aquella que no causa injusticia a otro» es un enunciado vacío y tautológico -no dice otra cosa que es libertad conforme a justicia la que no implica injusticia hacia otro-. El corolario que nuestro autor hace seguir a la constatación de la insuficiencia de ese criterio de la libertad legítima o según el derecho (rechtliche Freiheit) es el de que tal criterio de las leyes limitadoras (u «ordenadoras» del conflicto de libertades) es el de la posibilidad de acuerdo de todos respecto de las mismas.

Estas observaciones no sólo permiten, desde mi punto de vista, evitar una notoria dificultad interna en el sistema de los enunciados

${ }^{8}$ Acerca de la distinción entre un sentido de «daño» o «perjuicio», más próximo a lo empírico-descriptivo -como afectación adversa o menoscabo por la acción de alguien a los intereses de otros (harm)- y el sentido normativo, de trato injusto o acción injusta hacia otro, o que viola derechos de éste, para el que, con González Vicén, he utilizado el término «lesión», cifr. Joel Feinberg, 1984, págs. 34 y 35 , y 105 y ss. El concepto de «lesión» como injusticia es el que Kant presenta en los momentos esenciales de su teoría del derecho, en los que el término utilizado es el de Unrecht; como en la fórmula jurídica neminem laede que él transcribe como thue niemanden Unrecht (1978 pág. 96, $A k$. 236, también en pág. 98, Ak. 238). En la réplica a Benjamin Constant sobre Un supuesto derecho de mentir por filantropía, Kant utiliza la distinción de que hablamos como réplica al francés, quien «ha confundido la acción por la que alguien perjudica [schadet] (nocet) a otro (...) con aquella por la que comete una injusticia [Unrecht thut] (laedit) con él (págs. 65 y 67. Ak. VIII, págs. 428 y 499). En una nota de la «Introducción» a la Rechtslehre -pág. 99, Ak. 238- ha distinguido también entre «causar daño» (schaden) y «violar el derecho de otro» (seinem Rechte Abbruch Thut). La noción de «lesión-injusticia» había sido ya definida por Kant, en las Lecciones sobre la ética, en términos muy adecuados para lo que me ocupa en estas páginas -como oppositio iuris alterius o «acción que es contraria a la ley del otro, pues lesiono a una persona que tiene derecho a exigirme algo que es necesario según leyes universales del arbitrio» (págs. 87 y 89. Ak. 279 y 281-282)- vuelve a presentarse en la Doctrina del derecho cuando ésta sostiene: «Si mi acción puede conciliarse con la libertad de todos según una ley general, me causa lesión(Unrecht) aquél que me obstaculiza en ello, pues este obstáculo no puede conciliarse con la libertad según leyes generales» (pág. 81, Ak. 230-231). 
explícitos de nuestro autor, sino que conduce a una cuestión de mucho mayor calado en aquél: la de la remisión a leyes universales presente en todas y cada una de las formulaciones del principio de libertad en el Derecho.

Y bien, es esta remisión a la idea o principio de legislación sobre la libertad según leyes universales -o «leyes universales de libertad», en la expresión completa de Kant- la que contiene los rasgos más profundos y decisivos de su filosofía jurídica. Sólo desde su consideración podrá distinguirse ésta de las posiciones, bien conocidas, de un buen número de los representantes de la «teoría política de la libertad negativa», para quienes el criterio de la justicia y de la legitimidad del derecho se concibe únicamente en términos de la maximización del «libre juego» de las acciones individuales «espontáneas» o no obstaculizadas, por su valor instrumental para la obtención de resultados sociales óptimos, concebidos, a su vez, en términos pragmáticos de satisfacción de deseos, fines o intereses de los arbitrios empíricos.

Para comprender las ideas de Kant sobre el derecho y la política a la luz del conjunto de su filosofía práctica deberá, entonces, tomarse en serio la cláusula o condición «según leyes universales de libertad», que convierte la legislación jurídica en algo más que un orden positivo de coexistencia de libertades (al que el propio autor se refiere, desde lo que hoy podríamos llamar un concepto del derecho desde un punto de vista externo, como «la posibilitación de la máxima libertad, es decir, el antagonismo absoluto de sus miembros, con la más exacta determinación y seguridad de los límites de la misma») ${ }^{9}$, determinando su acuerdo con la Idea de derecho o justicia. Pienso que es dicha condición la que incorpora el contenido normativo fundamental -esto es, el criterio de justicia- para la relación entre libertades externas, que el concepto de derecho «según la idea de la razón práctica» contiene.

Que el derecho no es sólo un producto de la razón pragmática -y, así, como algunos autores han pretendido en su interpretación de las fórmulas de la Rechtslehre, un «conjunto de cálculos de igualdad legal» ${ }^{10}$-, es una de las tesis fundamentales del kantismo, desde la primera Crítica hasta la Metaphysik der Sitten, de la que constituye uno de los rasgos esenciales: como conjunto de principios para nuestras interrelaciones como sujetos de libertad, no podemos renunciar a pensar el derecho desde la razón práctico-moral. Ahora bien, ello significa que la legislación jurídica debe pensarse y fundamentarse -y las declaraciones de Kant al respecto son inabarcables- desde las

${ }^{9}$ Idea de una historia universal... Ak. VIII, pág. 21; 1981, pág. 49.

${ }^{10}$ George Kelly, 1969, pág. 520. 
condiciones de la razón para los principios de nuestra conducta, que es lo que precisamente contienen el «concepto moral del Derecho» y el «principio universal» del mismo.

Los principios de la razón práctico-moral, y tanto los de la ética como los de la teoría de la justicia, son «principios (o leyes) de libertad» en el sentido que esta expresión tiene en el núcleo mismo de la filosofía moral kantiana desde la Dialéctica trascendental: el de los principios que, a diferencia de las leyes de la naturaleza, «establecen lo que debe suceder, aunque nunca suceda», dando lugar al uso práctico de la razón: «práctico es todo lo que es posible mediante libertad». Ahora bien, la idea central de la filosofía moral kantiana (la que se sintetiza en el «principio supremo de la moral» o del «imperativo categórico») enuncia como condición de todas las leyes y deberes morales la de que éstos deben proceder de la voluntad racional de todos y cada uno de los individuos humanos, los cuales deben por tanto considerarse a sí mismos y a cada uno de los demás como legisladores de esos principios constrictivos de la libertad de los arbitrios subjetivos empíricos. La idea de libertad en este sentido primordial, «piedra angular de todo el edificio de un sistema de la razón pura ${ }^{11}$, tiene que presidir la construcción de todos los principios prácticos, también los de la filosofía del derecho.

Huelga insistir de nuevo en que no se trata aquí de intentar recuperar para el derecho, o reintroducir por otra puerta, la autonomía en la determinación del arbitrio a la acción (distintiva de la obligación moral) que, en tanto principio de unión de voluntades, da lugar a la comunidad ética, y con la que «sería contradictorio» el poder de coacción que caracteriza al derecho, «ya que aquélla ya en su concepto lleva consigo la libertad respecto de toda coacción ${ }^{12}$. Sin embargo, la exigencia de consideración de uno mismo y de todos los otros, como sujetos de libertad en relación con los principios a los que someten sus acciones, ha de mantenerse si el sujeto de derecho ha de seguir siendo -y para el autor de la Rechtslehre no puede ser de otro modo- una «persona moral» y, por lo tanto, «no sometida a otras leyes que aquéllas que ella misma se da, bien sola, o bien, al menos, de consuno con otras».

Esa condición de autogobierno recogida en la condición de «validez universal», que la idea de justicia impone a la legislación jurídica, tiene su lugar preferente en la idea reguladora de la «voluntad universal» o «voluntad de todos unificada a priori», convertida

${ }^{11}$ Crítica de la razón pura, BX, A 800/B 828, A802/B830; 1978, págs. 16, 627 y 628. Crítica de la razón práctica, $A k$. V, pág. 4; 1975, pág. 12

${ }^{12}$ La religión dentro de los límites de la mera razón, Ak. VI, págs. 95 y 96; 1981, págs. 95 y 96. 
en criterio de legitimidad de la legislación del Estado: «la voluntad concordante y conjunta de todos, en cuanto cada uno decide para todos, y todos para cada uno, esto es, la voluntad colectiva del pueblo, puede únicamente ser legisladora». Es, de nuevo en la filosofía del derecho, este principio de autolegislación el que hace posible la condición de validez universal que hemos visto enunciada en las fórmulas kantianas del concepto racional de derecho; por ello ha podido decirse que «la voluntad unida del pueblo es la posibilidad de producir la ley universal» ${ }^{13}$.

La huella del admirado Rousseau, innegable en tales ideas, y, rastreable hasta el principio mismo de autonomía moral ${ }^{14}$, se deja sentir con fuerza, desde los primeros pasos de la filosofía del derecho, en la noción de lo que Kant denomina «el derecho de la humanidad en la persona de cada uno». Situada en la Introducción a la Rechtslehre como eje mismo de la distinción entre deberes de justicia y deberes de virtud, aquélla incorpora el mandato primero (y «negativo») del principio de la moral, formulado en la Fundamentación de la metafísica de las costumbres como «principio de la humanidad como fin en sí misma», y reiterado en calidad de principio de las obligaciones jurídicas (que «consiste en afirmar nuestro propio valor como hombres en nuestras relaciones con los demás») como «vinculatoriedad del derecho de la humanidad en nuestra propia persona». Pues bien, el contenido normativo inmediato de ese principio se refiere a la libertad como no sometimiento a la voluntad particular de otro hombre, esto es, como autodeterminación en las relaciones («externas») con otros individuos. Si ya en las tempranas Anotaciones a las Observaciones sobre el sentimiento de lo bello y lo sublime -en que la influencia del autor del Émile se encuentra en su punto álgido- ${ }^{15}$ Kant insiste en que la "Sumisión (Unterwürfigkeit) de un hombre respecto de otro hombre» es «lo más penoso y antinatural», y lo mas contrario a toda dignidad, en la teoría del derecho se afirma como «único derecho innato» el de la libertad en términos no lejanos:

«Libertad -independencia del arbitrio compulsivo de otra persona-, siempre que se concilie con la libertad de los demás según una ley general, es éste único derecho originario, el cual corresponde a todo hombre por virtud de su propia humanidad. La igualdad innata, es decir, el derecho a no ser vinculado

\footnotetext{
${ }^{13} A k$. VI. págs. 223 y 314; 1978, pág. 65; 1989. pág. 128. Eduardo Bello, 1989, pág. 164.

${ }^{14}$ En este sentido, José Gómez Caffarena, 1983.

${ }^{15}$ Cifr., entre otros, Jean Ferrari, 1981, págs. 209 y 210, y Susan Shell, 1980, págs. 25 y ss.
} 
por otros a más de lo que uno puede vincularlos recíprocamente; de consiguiente, la cualidad del hombre de ser dueño de sí mismo (sui iuris) (...): todas estas facultades están ya comprendidas en el principio de la libertad innata y no pueden verdaderamente distinguirse de ella $(\ldots)^{16}$.

La relación entre estas ideas y la concepción «contractualista» del principio de legitimidad de la legislación, ya mencionada más arriba, es corroborada por los propios textos jurídico-políticos de Kant en los que la condición de autolegislación -de no sometimiento a la legislación de otra voluntad particular y, así, a otras leyes que aquéllas de las que uno pueda pensarse también como colegislador- se afirma como el criterio básico de justicia del derecho recogido en la idea regulativa de la «voluntad común legisladora». Creo que merece la pena citar el siguiente texto en su integridad:

«Todo derecho depende de leyes. Pero una ley pública, que determina para todos lo que les debe estar jurídicamente permitido o prohibido, es el acto de una voluntad pública de la cual procede todo derecho, y, por tanto, no ha de cometer injusticia contra nadie. Más, a este respecto, tal voluntad no puede ser sino la voluntad del pueblo entero (ya que todos deciden sobre todos y, por ende, cada uno sobre sí mismo), pues sólo contra sí mismo nadie puede cometer injusticia, mientras que, tratándose de uno distinto de uno mismo, la mera voluntad de éste no puede decidir sobre uno mismo nada que pudiera ser justo $(\ldots)^{17}$.

Me parece que las objeciones y reservas que puedan seguir manteniéndose frente a la presencia fundamental de la idea de autodeterminación, de raigambre rousseauniana, en la concepción de la libertad que Kant pone en la base de su teoría de la justicia, pierden decisivamente vigor ante los argumentos decisivos expuestos por el propio autor en apoyo de sus tesis centrales. Si, siguiendo a Berlin, la noción positiva de la libertad se interesa acerca de si es la propia persona, y no «fuerzas externas», la que determina su propia actividad -siendo en esa medida «sujeto de la propia vida y las propias decisiones», en vez de «instrumento de la voluntad de los demás»-, entonces sí hay tal idea de «libertad positiva» en las consideraciones fundamentales de la concepción kantiana de la constitución y la legislación del Estado según la «idea del Derecho».

${ }^{16} A k$. XX, págs. 88 y 94. Ak. VI, pág. 237-238; 1978, págs. 98 y 99.

${ }^{17}$ Sobre el dicho común: «Eso es correcto en teoría, pero no es posible en la práctica». Ak. VIII, págs. 294-295; 1986, pág. 33. 
Pero «alejar», por todo ello, las posiciones del autor de Teoría y práctica del «ideal de la libertad negativa», sólo puede hacerse si éste se reduce, a su vez, significativa y unilateralmente, para identificarlo con el de ciertas concepciones del liberalismo del tipo de las mencionadas más arriba (y que podríamos llamar, también simplificadoramente, «economicistas» o «utilitaristas»). No veo, si no, cómo puede expulsarse de la tradición filosófica liberal sobre la libertad al autor de la conocida crítica del gobierno paternalista («en el que los súbditos -como niños menores de edad, incapaces de distinguir lo que les es verdaderamente beneficioso o perjudicial- se ven obligados a comportarse de manera meramente pasiva»), como «el mayor despotismo imaginable» en nombre de un «principio de libertad» según el cual: «nadie me puede obligar a ser feliz a su modo (tal como él se imagina el bienestar de otros hombres), sino que es lícito a cada uno buscar su felicidad por el camino que mejor le parezca $(\ldots)^{18} \gg$.

La distancia que separa a Kant de aquellos liberales para quienes el valor de la no interferencia en la acción individual se piensa pragmáticamente en función de un valor ulterior de eficiencia (esto es, como el mejor instrumento para la satisfacción de lo que aquél llamaría «fines de felicidad»), es indudable si se atiende a la consideración de principio último que, en su filosofía del Estado y la política, se da al derecho de los hombres a regir sus propias vidas:

«Porque a los seres dotados de libertad no les basta el goce de una vida agradable, que también les pueden proporcionar otros (entre ellos el Gobierno); lo que importa es el principio con arreglo al cual se procura ese goce (...). (...) El derecho de los hombres necesariamente debe preceder a toda consideración de bienestar, pues se trata de algo sagrado por encima de cualquier precio (de utilidad) y que ningún gobierno, por muy benéfico que sea, puede tocar» ${ }^{19}$.

Las dificultades de comprensión a que conducen los intentos de emplazar la obra kantiana en una de los dos opciones, rivales e incompatibles, de la alternativa entre conceptos de la libertad, reaparece si consideramos algunos otros aspectos de su teorización de la libertad en el estado jurídico. Así ocurre, desde mi punto de vista, si se traslada la atención -con un mínimo de detenimiento y no sólo en sus lemas o formulaciones, y según categorías fijadas de antemano- desde las posibles definiciones genéricas de la libertad a los ámbitos

${ }^{18} \mathrm{Ibid}$, Ak. VIII, págs. 290-291; 1986, págs. 27 y 28.

${ }^{19}$ El conflicto de las Facultades. Ak. VII, pág. 87 nota. En Filosofía de la historia, 1979, pág. 120. 
específicos en que ésta opera (es decir, a lo que se ha llamado intencionadamente «las libertades»).

Llegados a este punto, la primera constatación que podría obtenerse es la de la presencia inmediata y destacada de propuestas que cabe situar sin mayores dificultades en la tradición «liberal» de la libertad (o, en la terminología consolidada, en la del concepto «negativo» de ésta), lo que, por lo demás, es bien sabido que suele ocurrir cuando la cuestión se plantea en ese terreno plural de «las libertades». Tanto la reivindicación prioritaria y decisiva por Kant de la libertad intelectual y académica, como su insistente y clara defensa de la libertad económica parecen abonar sin más esa respuesta ${ }^{20}$.

La defensa de la libertad económica tiene, en la teoría y las convicciones sociales de este autor, explicaciones tan diversas e importantes como su detenida teorización de la propiedad privada -en tanto plasmación y extensión de la libertad personal y, de nuevo, según el criterio regulador de la «idea de una voluntad universal»-; o la creencia burguesa, mucho menos argumentada, de la constitución progresiva de la sociedad civil (de propietarios independientes que intercambiarían sus mercancías en un mercado de iguales) a través de la competencia no obstaculizada de iniciativas y esfuerzos individuales.

Pero son, sin duda, las libertades de pensamiento y expresión pública las más vehementemente reivindicadas en el pensamiento del regiomontano. Sin necesidad de volver a los aspectos o componentes de esa esfera de la libertad más próximos a la ética -así, la libertad de conciencia, inasequible incluso para las leyes del Estado según el mismo concepto de derecho, o la libertad religiosa-, la libertad de investigación en el ámbito científico, filosófico o académico y, sobre todo, la libertad de expresión pública en materias políticas y de crítica al gobierno (o «libertad de pluma»), juegan un papel difícilmente exagerable en la teoría kantiana del Estado de derecho y del «modo republicano de Gobierno».

La relevancia de la libertad de expresión política -«facultad de dar a conocer públicamente su opinión acerca de lo que en las disposiciones del soberano le parece haber de injusto para la comunidad»- llega hasta el punto de que ésta es constituida en «el único paladín de los derechos del pueblo» (al que «querer negarle esta libertad es arrebatarle toda pretensión de tener derechos frente al supremo mandatario» ${ }^{21}$ ). En atención a los propósitos declarados más arriba, me interesa, ante todo, estudiar las razones que justifican tales pronunciamientos.

\footnotetext{
${ }^{20}$ Cifr., en este sentido, la completísima obra de Georges Vlachos, 1962, págs. 80 y ss., 375 y ss., entre otras.

${ }^{21} A k$., VIII, pág. 304; 1986, págs. 46 y 47.
} 
Un primer tipo de explicaciones aparece inmediatamente (y así son explícitamente aducidas en los textos correspondientes) a la luz del conocido rechazo kantiano de cualquier derecho de rebelión o resistencia de los súbditos frente a la legislación del soberano. La libertad de expresión y crítica públicas tiene como objeto hacer posible la evitación y rectificación de los errores o injusticias «objetivas» de la acción legislativa y política, la información al soberano sobre la necesidad o deseabilidad de reformas, o la discusión y argumentación sobre ellas. Se trata, en suma, de la contribución de aquella libertad a lo que el lenguaje político tradicional llamaría «el buen gobierno»y, en la construcción kantiana, a sostener la posibilidad de la tesis (que Kant opone explícitamente a Hobbes) de que «el pueblo tiene derechos inalienables frente al soberano, aunque no puedan ser derechos de coacción».

Pero me interesan más ahora, en relación con las ideas de que se ocupan estas páginas, un segundo tipo de consideraciones que Kant expone, asimismo, como fundamento de esa libertad «negativa», y que me parecen especialmente certeras y aleccionadoras. Me refiero a la vinculación directa y sustancial que sus escritos establecen entre la existencia de discusión y crítica públicas de las leyes y la política del Estado, y la libertad de pensamiento sin más, y, por ende, con la capacidad para cada individuo de pensar por sí mismo y no depender, por consiguiente, del juicio y la voluntad de otro:

«El poder externo que priva a los hombres de la libertad de comunicar públicamente sus pensamientos los priva también de la libertad de pensar (...).

«Es difícil para cada hombre en particular lograr salir de esa incapacidad [de servirse de la propia inteligencia sin la guía de otro] (...). Pero ya es más fácil que el público se ilustre por sí mismo y hasta, si se le deja en libertad, casi inevitable. (...) Para esta ilustración no se requiere más que una cosa, libertad; y la más inocente entre todas las que llevan ese nombre, a saber: libertad de hacer uso público de su razón íntegramente ${ }^{22}$.

Para comprender el significado de estos argumentos en la filosofía jurídico-política kantiana es necesario referirse a uno de los aspectos más complejos y criticados de ésta (en el que no puedo detenerme todo lo que su importancia requeriría). Se trata de la separación que el escrito sobre Teoría y práctica y la Doctrina del

${ }^{22}$ Cómo orientarse en el pensamiento. Ak. VIII, pág. 144: 1983. págs. 60-6 1. Qué es Ilustración, $A k$. VIII, págs. 35 y 36; 1981, págs. 25-28. 
derecho establecen entre la exigencia de autolegislación, o consentimiento de todos y cada uno de los individuos a las leyes públicas, y la participación efectiva en la configuración de éstas mediante el voto para la elección de diputados o representantes en el poder legislativo efectivo. El ejercicio del poder legislativo por los representantes de los ciudadanos (designados por el voto mayoritario de éstos) constituye la «forma republicana del Estado» o de la soberanía de hecho (Form der Beherrschung), en tanto que la idea de la voluntad universal se traduce -en el «modo republicano de gobierno» (Form der Regierung)- en criterio regulativo moral o de justicia, de la legislación del soberano (sea éste un monarca o una asamblea de representantes).

Sólo esa separación permite, entre otras cosas, a Kant -sin una contradicción pragmática inmediata con el principio racional del autogobierno de todos- restringir drásticamente la condición de la ciudadanía activa (la de los que son miembros activos del Estado, con «derecho a voto en la legislación»). De ella quedan excluidas las mujeres (en consonancia con una concepción patriarcal de la que es buena muestra la teorización de la sociedad familiar en la «Doctrina del derecho privado»), así como también aquellos que no puedan sostenerse económicamente por sí mismos y dependan de otros («se ven forzados a ponerse a las órdenes de otros») para poder vivir.

Esta limitación de la ciudadanía activa no sólo es insuficiente y erróneamente justificada por nuestro autor (en cuanto a su premisa de hecho fundamental que afirma la conexión entre trabajo por cuenta ajena y dependencia en las opiniones o juicios políticos), sino que es incompatible con algunas de sus propias posiciones: la independencia civil deja de ser un derecho de todos (recuérdese la declaración, recogida más arriba, de que «la cualidad del hombre de ser su propio dueño está contenida a priori en el derecho a la libertad como único derecho innato») para convertirse, por el contrario, en una condición de hecho para la asignación o negación normativa del derecho primordial de la ciudadanía; de manera que el orden empírico de desigualdad y dominación de la sociedad civil tradicional se introduce en lo que se pretendía construcción puramente normativo-racional de los derechos según la condición a priori del contrato ${ }^{23}$. La atribución de consecuencias jurídico-normativas a la dependencia económica contradice, asimismo, la propia posición kantiana sobre la igualdad jurídica «perfectamente compatible con la máxima desigualdad, cuantitativa o de grado, en sus posesiones».

Me he detenido en este momento, sin embargo, en tan desafortunada construcción para destacar un aspecto de la misma que considero

${ }^{23}$ Véase, en este sentido, Manfred Riedel, 1981, págs. 604 y ss., José Luis Villacañas Berlanga, 1987, págs. 222-224. 
digno de atención para la filosofía política y, desde luego, importante para la teoría de la libertad que me ocupa. La justificación de la restricción socioeconómica para la ciudadanía activa no responde, en efecto, en el caso de Kant, a los patrones más conocidos de la propiedad territorial, de la contribución financiera al sostenimiento del Estado, o a la posibilidad de ocio reflexivo y dedicación a los asuntos públicos que da la despreocupación económica por la propia subsistencia. El criterio kantiano refiere la independencia a quien subsiste económicamente por la «venta de lo que es suyo» («incluyendo en este concepto toda habilidad, oficio, arte o ciencia»), por lo que «no está al servicio de nadie» ${ }^{24}$. Pero lo relevante para el autor, como razón de esas determinaciones, es la «dependencia»o «sometimiento» a la protección y, así, a la voluntad de otros individuos que tal situación supone: aquéllos se ven, en definitiva «obligados a ponerse a las órdenes de otros» lo que invalida su condición de sujetos individuales de la política republicana.

Y si la aserción de hecho que esa explicación contiene es, repito, problemática, lo que importa, en mi opinión, es la premisa filosófica de la que aquélla parte, según la cual la independencia en el juicio, la capacidad de «pensar por sí mismo», es condición sustantiva de la libertad política del individuo en el Estado. La idea de la libertad del ciudadano no significa sólo una situación «negativa» de ausencia -en cierta medida o en ciertas esferas de la acción- de la coerción legal, sino que se relaciona decisivamente con el valor de la autodeterminación o autogobierno del individuo en la comunidad.

El escrito de Kant en respuesta a la pregunta ¿Qué es Ilustración? proporciona reflexiones inapreciables en torno a dichas ideas: la relación que allí se establece entre la libertad de expresión y configuración de la opinión pública, y madurez o mayoría de edad (Mündigkeit), no hace de la Ilustración un valor relativo al bien del Estado republicano -al posibilitar la existencia de la opinión pública de los ciudadanos- sino que, a la inversa, considera la libertad de discusión pública (el uso público de la razón) como un momento imprescindible de la «emancipación» en el pensamiento, de la asunción de «la decisión y el valor de servirse de la propia razón sin la tutela de otro»:

«Mediante una revolución acaso se logre derrocar el despotismo personal y acabar con la opresión económica a política, pero nunca se consigue la verdadera reforma de la manera de

${ }^{24} A k$., VI, págs. 314-315; 1989, pág. 144 y $A k$. VIII, pág. 295; 1986, pág. 34. El mismo autor reconoce que «es difícil reconocer los requisitos que ha de satisfacer quien pretenda la posición de un hombre que sea su propio señor». 
pensar; sino que, nuevos prejuicios en lugar de los antiguos, servirán de riendas para conducir al gran tropel. (...) El uso público de su razón le debe estar permitido a todo el mundo y esto es lo único que puede traer ilustración a los hombres $(\ldots)^{25} \gg$.

No creo que Elías Díaz quede, ni mucho menos, tranquilo o satisfecho con esta exposición del derecho primordial de la libertad de pensamiento y expresión pública, en relación al valor último de la autodeterminación (también podemos llamarla «autonomía») en la configuración de la propia vida y las relaciones con los otros, si todo ello ha de tener como corolario parcial la limitación de la «libertad democrática», es decir del derecho de voto $^{26}$. Que yo comparta su opinión en ese punto no creo que importe, por lo demás, gran cosa a este maestro de la «concordia discorde» ( y los que le conocen saben bien el sentido que tiene aquí la expresión kantiana). Presumo, en cambio, que sí habrá de gustarle otra consecuencia que el propio Kant extrae de su convicción sobre la urgencia de la ilustración como maduración en la libertad y que él mismo expone en palabras inmejorables:

«Confieso que no puedo acomodarme a esta expresión de la que se sirven también hombres sensatos: cierto pueblo (en vías de elaborarse una libertad legal) no está maduro para la libertad; y así también: los hombres en general no están aún maduros para la libertad de creencia. Según un supuesto tal la libertad nunca tendrá lugar; pues no se puede madurar para ella si no se ha sido ya antes puesto en libertad (hay que ser libre para poder servirse convenientemente de las propias fuerzas en la libertad). Los primeros intentos serán desde luego burdos, comúnmente incluso ligados a un estado más molesto y más peligroso que cuando se estaba bajo las órdenes, pero también bajo la providencia, de otro; pero no se madura jamás para la razón si no es por medio de los propios intentos (que uno ha de ser libre de poder hacer)» ${ }^{27}$.

${ }^{25} A k$. VIII, págs. 35-37; 1981, págs. 25-28.

${ }^{26}$ Susan Shell explica de este modo algo de lo que aquí he intentado explicar: «el curso de la ilustración humana, o «la emancipación de la tutela autoimpuesta» requiere [para Kant] que la libertad de pensamiento prevalezca sobre la libertad de voto (...). La libertad para publicar es la libertad externa del espíritu. El derecho del individuo a participar en el libre intercambio (de bienes o de ideas) precede a su derecho a elegir representantes políticos», 1980, págs. 172 y 173.

${ }^{27}$ Religión... Ak. VI, pág. 188 nota; 1981, págs. 234-235 nota. 


\section{Bibliografía}

Las obras de Kant citadas se acompañan de la referencia al volumen y página de la edición berlinesa, hoy canónica, KANTS WERKE, Akademie Textausgabe, Berlín, 1902 en adelante. Las traducciones castellanas utilizadas son las siguientes:

-Crítica de la razón pura. Trad. de Pedro Ribas, Madrid, Alfaguara. 1978.

-Crítica de la razón práctica. Trad. de Emilio Miñana y Manuel García Morente, Madrid, Espasa-Calpe, 1975, (primera edición de 1913).

- Metafísica de las costumbres. Trad. de Adela Cortina y Jesús Conill. Madrid, Tecnos, 1989. La «Introducción» a esta obra la cito por la edición Introducción a la teoría del derecho. Trad. de Felipe González Vicén, Madrid, Centro de Estudios Constitucionales, 1978 (primera edición, 1954).

-En torno al tópico: «Tal vez eso sea correcto en teoría pero no sirve en la práctica» y Sobre un presunto derecho de mentir por filantropía. Trad. de M. Francisco Pérez López y Roberto Rodríguez Aramayo, Madrid, Tecnos, 1986.

-La paz perpetua. Trad. de F. Rivera Pastor, Madrid, Espasa-Calpe, 1979 (primera edición, 1946).

- La religión dentro de los límites de la mera razón. Trad. de Felipe Martínez Marzoa, Madrid, Alianza Ed., 1981 (primera ed. 1969).

-Idea de una historia universal en sentido cosmopolita, ¿qué es la Ilustración? y El conflicto de las Facultades (ésta en su segunda parte. "Si el género humano se halla en progreso constante hacia mejor»), son citadas por la trad. de Eugenio Imaz en el volumen Filosofía de la historia, México, Fondo de Cultura Económica, 1981 (primera ed. 1941). -Cómo orientarse en el pensamiento. Trad. de Carlos Correas, Buenos Aires, Leviatán, 1983.

-Lecciones de ética. Trad. de Concha Roldán y Roberto Rodríguez Aramayo, Barcelona, Crítica, 1988.

\section{Obras de otros autores citadas:}

-Bello, Eduardo: «La lectura kantiana del «Contrato social». En Javier Muguerza y Roberto Rodríguez Aramayo (eds.), Kant después de Kant (En el bicentenario de la Crítica de la razón práctica). Madrid, Tecnos-Instituto de Filosofía del CSIC, 1989.

-Berlin, I.: Four Essays on Liberty, Oxford Univ. Press, 1979 (primera ed. 1969). Trad. de Belén Urrutia, Julio Bayón y Natalia Rodríguez Salmones, Madrid, Alianza Ed., 1988.

-Bobbio, N.: «Deux notions de liberté dans la pensée politique de Kant». En varios autores, La philosophie politique de Kant, París, Institut International de Philosophie Politique, 1962. Trad. castellana de Juan Carlos Bayón, en Bobbio, Estudios de historia de la filosofía: De Hobbes a Gramsci, Madrid, Debate, 1985. 
-Feinberg, J.: Harm to Others. The Moral Limits of the Criminal Law, Oxford University Press, 1984.

-Ferrari, J.: Les sources françaises de la philosophie de Kant. Université de Lille, 1981. -Gómez Caffarena, J.: El teísmo moral de Kant, Madrid, Ediciones Cristiandad, 1983.

-González Vicén, F.: La filosofía del Estado en Kant. Edic. original Universidad de la Laguna, 1952. Reed. en González Vicén, ¿De Kant a Marx? Estudios de historia de las ideas, Valencia, Fernando Torres, 1984, por la que cito.

-Kelly, G. A.: «The Structure and Spirit of Legality in Kant». Journal of Politics, 31, 1969, págs. 513-527.

Riedel, M.: «Trascendental Politics? Political Legitimacy and the Concept of Civil Society in Kant». Social Research 48, 1981, págs. 588-613.

-Shell, S. M.: The Rights of Reason: a Study of Kant's Philosophy and Politics, University of Toronto Press, 1980.

-Villacañas Berlanga, J. L.: Racionalidad crítica. Introducción a filosofía de Kant, Madrid, Tecnos, 1987.

-Vlachos, G.: La pensée politique de Kant, París, Presses Universitaires de France, 1962. 